\title{
Piloting the Domestic Violence Healthcare Providers' Survey for Use in Uganda: Testing Factorial Structure and Reliability
}

\author{
Stephen Lawoko ${ }^{1,2^{*}}$, Milton Mutto ${ }^{3}$, David Guwattude ${ }^{2}$ \\ ${ }^{1}$ Department of Public Health Sciences, Karolinska Institutet, Stockholm, Sweden \\ ${ }^{2}$ Department of Epidemiology, Makerere University, Kampala, Uganda \\ ${ }^{3}$ Pincer Group International, Kampala, Uganda \\ Email: "stephen.lawoko@ki.se
}

Received June $5^{\text {th }}, 2012$; revised August $7^{\text {th }}, 2012$; accepted September $8^{\text {th }}, 2012$

\begin{abstract}
Background: A number of instruments to assess healthcare workers readiness to screen for Intimate Partner Violence (IPV) in healthcare are now available to researchers. Before application in new settings however, pilot studies assessing their validity are warranted. Aim: In this pilot study, we assessed the factorial structure and reliability of the Domestic Violence Healthcare Provider Survey Scale (DVHPSS) for future use in Uganda. Method: A convenient sample of healthcare workers at a referral hospital in Arua district, Uganda $(\mathrm{n}=90)$ responded to the DVHPSS. Exploratory factor analysis using principle components and Cronbach's alphas testing for internal reliability were applied on 86 complete individual responses to items of the DVHPSS. Bivariate correlations were run to assess scale distinctiveness. Results: All but one item of the DVHPSS exhibited significant factor loadings. Most subscales emerging from the factor analysis (i.e. Blame victim, professional role resistance and system support sub-scales) were congruent with the original scales. A split of the original victim/provider safety scale was however evident in the current data, forming two distinct scales i.e. victim and provider safety respectively. Items of the original perceived self-efficacy scale exhibited significant factor loadings but under separate factors, indicating that they may not be measuring a uni-dimensional concept in the Ugandan healthcare context. Conclusions: This data confirms the validity and reliability of the DVHSS for use in Uganda. It is however recommended that items be scored in accordance to the specific sub-scales revealed in this study, to improve the structural validity of any assessment using the DVHPSS in Uganda.
\end{abstract}

Keywords: Domestic Violence Survey; Healthcare; Factorial Structure; Reliability; Uganda

\section{Introduction}

Intimate Partner Violence against Women (IPV), defined as any act in partner relations that results or is likely to result in physical, sexual or psychological harm or suffering to women (e.g. threats of violence, coercion, deprivation of liberty) (UN, 1993) has long been recognized as a public health concern globally. Women experiencing IPV report physical ailments as a result of physical assaults (Aimakhu, Olayemi, Iwe, Oluyemi, Ojoko, Shoretire, Adeniji, \& Aimakhu, 2004; Koenig, Ahmed, Hossain, \& Khorshed, 2003; Fawole, Aderonmu, \& Fawole, 2005), reproductive morbidity in the form of terminated pregnancies and still births, child loss within the first years of birth (Garcia-Morena, Jansen, Ellsberg, Heise, \& Watts, 2005; Kishor \& Johnson 2004), and symptoms of depression, anxiety, post-traumatic stress and suicide dispositions (Koss, 1990; Heise \& Garcia-Moreno, 2002; Tjaden \& Thoennes, 2000; Tolman \& Rosen 2001; Petersen, Gazmararian, \& Clark, 2001). Despite the high risk for morbidity, victims of IPV appear to use and seek sanctuary in formal organisations like health care to a much lower degree when contrasted with non-abused women. Recently, the World Health Organisation (WHO) reported that fear of retaliation from the abuser and stigmatizing attitudes from service providers and community at large to accounted for discrepancies in health seeking behaviour in this risk group, with no distinction between low, middle and high

\footnotetext{
${ }^{*}$ Corresponding author.
}

income countries (WHO, 2005), indicating institutional barriers in detection and management of IPV globally. The healthcare system thus has in recent years been challenged to get more actively involved in detection and management of IPV through systematic screening for the phenomena among women visiting healthcare settings.

Screening for IPV in healthcare requires the routine involvement of healthcare workers in the detection and management of IPV among clients who may or may not present with direct signs of victimization/abuse (AMA, 1992). The rational for universal screening is strong. First, anecdotal evidence suggests that merely recognizing and validating women's situation with regard to battering may have far-reaching effects on their responses to treatment options and ultimately their health (AMA, 1992). Secondly, self-reports from women indicate that they are comfortable responding to IPV inquiries in healthcare settings (Stenson, Sidenvall, \& Heimer, 2005). Congruent with this view, healthcare professionals themselves acknowledge that routine screening is likely to improve female clients satisfaction with care (John, Lawoko, \& Oluwatosin, 2011). A consensus between both stakeholders notwithstanding, evidence suggests that only $8 \%-10 \%$ of healthcare personnel routinely screen for IPV (Erikson, Hill, \& Siegal, 2001; Roelens, Verstraelen, Van Egmond, \& Temmerman, 2006), which suggests the presence of barriers associated with healthcare providers' insufficient knowledge and training in screening, professional roles governing the provider-client relations, (e.g. mutual re- 
spect, fear of offending clients, etc.), healthcare providers' individual attitudes towards IPV, and cultural values (Erikson, Hill, \& Siegal, 2001; Roelens, Verstraelen, Van Egmond, \& Temmerman, 2006; Waalen, Goodwin, Alison et al., 2000; John, Lawoko, \& Svanstrom, 2011; Maiuro, Vitaliano, Sugg et al., 2000). A vital question that arises thus with regard to screening concerns the readiness of healthcare providers to screen for practices like IPV in healthcare settings and how such readiness can be measured.

A few instruments have been made available to researchers for the assessment of readiness to screen for IPV (Short, Alpert, Harris, \& Surprenant, 2006; Rodríguez, Bauer, McLoughlin, \& Grumbach, 1999). Among the most comprehensive of them however is the Domestic Violence Healthcare Provider Survey Scales (DVHPSS) (Maiuro, Vitaliano, Sugg, Thompson, Rivara, \& Thompson, 2000). The scale measures healthcare professsionals' readiness to screen in terms of their perceived knowledge, efficacy in screening, conflicting professional roles, availability of social support networks to which IPV victims can be referred, client safety challenges, and health care workers' general attitudes towards such screening. Though assumed to be universal, such instruments need to be piloted and validated before their application in new context. In this study, the instrument is piloted in Arua district, Uganda, before it is used in a larger study to assess readiness to screen among healthcare providers in 3 districts of Uganda. The rationale of testing the validity of instruments used in healthcare research in general, before application in explanatory modelling in new populations deserves some acknowledgement, as an important area of healthcare research. Healthcare systems vary in their structure, as do healthcare cadres in their training and attitudes from one con- text to another. The structure of indicators of readiness to screen for IPV thus could vary between dissimilar populations.

Validity is an important issue when using abstract measures/ questions to represent theoretical concepts. In general, an instrument is said to be valid when it measures what it is purported to measure (Nunnaly, 1978). Some important aspects of validity include factorial structure and reliability which together account for the structural validity of an instrument. Factorial structure attempts to distinguish underlying concepts a set of questions/items/variables may be capturing, without imposing a preconceived structure on what these questions are measuring. When measuring readiness to screen for IPV based on a set of questions concerning readiness in general, researchers thus are interested in understanding the sub-concepts (sub-scales) that may form parts of readiness as a whole, i.e. the factorial structure of readiness to screen.

Reliability refers to the accuracy and precision with which an instrument/subscale captures what it is purported to capture (Thorndike, Cunningham, Thorndike, \& Hagen, 1991). Internal consistency is one form of reliability measure which assesses individuals performance from item to item when data is collected using a single form (Cronbach \& Meehl, 1995). In this study, the concepts that emerge from the factor analysis are tested for reliability.

The objective of this study thus is to assess the structural validity of the DVHPSS in terms of its factorial structure and internal reliability. The following research questions are addressed:

1) Do the items of the DVHPSS capture adequately the underlying constructs they are purported to measure when applied in the Uganda healthcare context (i.e. the question of factorial stability)?

2) How accurately do the constructs/subscales of the DVHPSS capture what they are purported to capture in the Ugandan context (i.e. the question of internal consistent/reliability)?

\section{Methods}

\section{Study Settings, Design and Participants}

This cross-sectional study was carried out among healthcare providers a district referral hospital in Arua district, Uganda. The healthcare providers at the hospital have not previously undergone any formal training in screening for IPV among their female clients. A total of 90 healthcare workers, obtained through convenient sampling of participated in this pilot study. The sample size optimal for a structural validity test is dependent on the number of items the instrument in question contains. Since the domestic violence healthcare survey instrument consists of about 30 items, approximately 3 times as many participants are needed to run structural validity tests (i.e. 90 participants). A total of 86 participants had complete responses to all items and were thus used for this analysis.

The questionnaire was self-administered and was accompanied by an information letter.

\section{Ethical Consideration}

Information letters informing participants of the aims of the study and their role accompanied the questionnaire. Voluntary participation, confidentiality and informed consent were emphasised. This study received ethical approvals from the Makerere University Research Ethics Committee and the Uganda National Council for Science and Technology, the two bodies responsible for scientific research in Uganda.

\section{Instrument Measures}

The Domestic Violence Health Care Provider Survey Scale measures healthcare providers' readiness to screen for IPV as well as actual screening activity (Maiuro, Vitaliano, Sugg, Thompson, Rivara, \& Thompson, 2000). The instrument has been previously validated with promising results in some countries including USA and Nigeria. The questionnaire, in its original format, is composed of the following 5 subscales:

The perceived self efficacy subscale scale (4 items) assesses providers own perceived efficacy in inquiring about IPV (details in Table 1).

The system support sub-scale (4 items) assesses a) healthcare providers' access to support networks for referral/management of IPV victims (details in Table 1).

The professional roles resistant/fear of offending clients subscale (6 items) assesses whether providers perceive inquiries about IPV may conflict with ethical issues governing their communication with clients (details in Table 1).

The blame victim sub-scale ( 7 items), assesses providers attitudes towards victims (details in Table 1).

The victim/provider safety sub-scale (10 items), assesses whether providers perceive inquiries about IPV from batterers to further jeopardize safety of victims and/or care provider.

All items require of the respondent to take a position on specific statements. The response alternatives to each statement range from 1 (strongly disagree) to 5 (strongly agree). 
Table 1.

Bivariate correlations between subscales: testing for distinctiveness.

\begin{tabular}{ccccc}
\hline & $\begin{array}{c}\text { Professional role } \\
\text { resistant/fear of offence }\end{array}$ & Victim/provider safety & Blame victim & Perceived efficacy \\
\hline Professional role resistant fear of offence & $0.31^{*}$ & & \\
Victim/provider safety & $0.30^{*}$ & $0.30^{*}$ & & \\
Blame victim & 0.14 & 0.01 & 0.09 & -0.15 \\
Perceived efficacy & $-0.25^{*}$ & -0.15 & 0.05 & \\
System support &
\end{tabular}

\section{Statistical Analysis}

Data cleansing: Prior to analyses, certain procedures were carried out to clean data. First, only participants who had responded to all items of the DVHSS were included in the analyses to reduce the likelihood of erroneous estimates as a result of missing data. Second, items were checked for normality using the skewness statistic and its confidence interval. Skewness statistic of magnitude zero is an indication of perfect symmetry (thus, confidence intervals including zero are an indication of normality). Relevant transformations (e.g. square roots, logarithm, inverse or reflection) were applied to transform skewed data.

Factor analysis and reliability test: An exploratory factor analysis (instead of a confirmatory one) was preferred, so as to avoid taking a preconceived position on which questions should be included under each sub-scale. It is plausible that certain sub-scales could in another context merge or split to form new sub-scales. Thus, exploratory factor analysis using principal component method was performed to test underlying factors and their stability as expressed in the factor loadings. Varimax rotation was applied to limit the number of high loadings under the same factor. This would enhance clearer identification of items emerging under each subscale. Criteria for the number of resulting significant factors was based on Kaiser Criterion and confirmed with scree plots (Carrol, 1957; Field, Aneja, \& Rosner, 2007). Items with factor loading of at least 0.30 were considered significant; this is based on criteria for significant correlation (Cohen, 1988). The contribution of emerging factors in explaining the total variation in the item pool was reported. Significant factors (i.e. those having a highest loading of over 0.30) were tested for internal consistency using Cronbach's Alpha. Alpha coefficients of at least 0.60 were considered significant, a threshold adequate for research purposes (Streiner \& Norman, 1989; Nunnaly, 1978). Where double loadings were evident, the item was assigned to the factor under which it loaded highest.

Scale distinctiveness: Bivariate correlations were run to investigate scale distinctiveness of the resulting factor solution (Streiner \& Norman, 1989; Nunnaly, 1978) (i.e. though some sub-scales may be correlated with each other, these correlations should not be close to one, as this would be an indication that the sub-scales are measuring an identical concept).

\section{Results}

\section{Sample Characteristics}

A total of 86 complete responses were received from the sampled health workers. Fifty five percent $(55 \%)$ were male.
Mean age of the sample was 38.8 years (st.dev $=8.9, \min =20$ $\& \max =58$ years). Majority were married $(72 \%)$ and of protestant religion $(42 \%)$. Occupation distribution was as follows: $32 \%$ of respondents were Nurses, $15 \%$ were mid wives, $10 \%$ were Medical Doctors and $43 \%$ were other health professionals. The average length of time in service was 11.8 years $($ st.dev $=$ $7.7, \min =1 \& \max =35$ ).

\section{Scale Factorial Structure}

When subjected to exploratory factor analysis, a five (5) factor structure emerged (Table 2) and were retained on account of the Kaiser Criterion (eigen values $>1$ ) and a confirmatory scree plot. The 5 factors extracted approximately $63 \%$ of the variability in the responses, and mainly reflected the subscales in their original format. Factor largely reflected the Blame victim subscale, explaining $24 \%$ of the variation in the total responses. Factor 2 reflected mainly a victim safety subscale (splitting the original victim/provider safety scale), explaining $12 \%$ of the total variation in responses. Factor 3, explaining $10 \%$ of variation in the total responses, represented mainly the System support subscale, though several items of the Perceived self-efficacy scale loaded high on the same factor. Factor 4 appeared to represent a provider safety scale (splitting the original victim/provider safety scale) and explained $9 \%$ of the variation in the total response. Finally, factor 5 represented largely the Professional role resistance/fear of offending clients subscale, explaining $8 \%$ of the variation in the total response.

\section{Item Performance}

Except for one item (i.e. "I have ready access to information detailing the management of IPV") all other items loaded above the minimum required threshold of factor loading 0.30 (Table 2). While most items had their highest factor loading under their original scale, the following observations were made: Most items of the professional role resistant/fear of offending clients scale loaded significantly under factor 5, with the exception of two items, which loaded highest under factor 3 (marked "*" in table). Most items of the "blame victim" subscale loaded highest under factor 1, with the exception of two items (marked “*” in table), which loaded highest under two separate factors. Items of the "provider/victim safety" split into two with victim safety items loading under factor 2 and provider safety under factor 4. System support items loaded highest under factor 3 , with the exception of 1 items which loaded highest under another factor. The different items of the "perceived self-efficacy" scale were split between factors $1-4$. Double loadings were observed for a number of items. In such cases, the highest loading was considered. 


\section{S. LAWOKO ET AL.}

Table 2.

Full factorial model: original subscales, principal components and cronbach's alphas.

\begin{tabular}{|c|c|c|c|c|c|}
\hline \multirow{2}{*}{$\begin{array}{l}\text { Sub-scale (cronbach's alpha in brackets) } \\
\text { Professional Role Resistance/Fear of offending the Patients (Alpha }=0.674) \text {. }\end{array}$} & \multicolumn{5}{|c|}{ Principal components } \\
\hline & 1 & 2 & 3 & 4 & 5 \\
\hline Asking patients about Intimate Partner Violence (IPV) is an invasion of their privacy. & 0.26458 & 0.22414 & 0.10509 & 0.05359 & -0.30597 \\
\hline It is demeaning to patients to question them about abuse. & 0.02759 & 0.12103 & -0.10580 & -0.12018 & 0.66400 \\
\hline If I ask non-abused patients about IPV, they will get very angry. & 0.12372 & 0.00620 & -0.07375 & 0.29308 & 0.61272 \\
\hline I am afraid of offending the patient if I ask about IPV. & 0.07892 & 0.07640 & 0.07834 & 0.15161 & 0.61623 \\
\hline I think that investigating the underlying cause of a patient's injury is not part of medical care. & 0.45560 & -0.09449 & 0.04960 & 0.21346 & 0.48501 \\
\hline It is not my place to interfere with how a couple chooses to resolve conflicts. & 0.29405 & -0.12491 & -0.35109 & -0.24918 & 0.28873 \\
\hline If patients do not reveal abuse to me, then they feel it is none of my business. & 0.03526 & -0.06605 & -0.62408 & 0.04356 & 0.12891 \\
\hline \multicolumn{6}{|l|}{ Blame victim $($ Alpha $=0.609)$} \\
\hline A victim must be getting something out of the abusive relationship, or else she would leave. & -0.34676 & 0.12906 & -0.25072 & -0.19670 & 0.10079 \\
\hline People are only victims if they choose to be. & 0.55005 & -0.27738 & 0.10308 & 0.38805 & 0.04338 \\
\hline When it comes to IPV victimization, it usually "takes two to tango." & -0.73624 & 0.01776 & -0.09615 & 0.03701 & 0.13267 \\
\hline I have patients whose personalities cause them to be abused. & -0.79630 & 0.02059 & 0.09070 & -0.00036 & -0.07798 \\
\hline Women who choose to step out of traditional roles are a major cause of IPV. & 0.00739 & -0.00857 & -0.12362 & -0.39457 & 0.22963 \\
\hline The victim's passive-dependent personality often leads to abuse. & 0.37624 & 0.16721 & 0.14302 & -0.20736 & 0.09079 \\
\hline The victim has often done something to bring about violence in the relationship. & 0.38787 & 0.42418 & 0.14463 & 0.20092 & -0.09460 \\
\hline \multicolumn{6}{|l|}{ Victim/provider safety $(0.600)$} \\
\hline $\begin{array}{l}\text { There is no way to ask batterers about their behaviours without putting the victims in more } \\
\text { danger. }\end{array}$ & -0.04019 & 0.51430 & 0.19516 & 0.32167 & -0.11720 \\
\hline I am afraid if I talk to the batterer, I will increase risk for the victim. & 0.01743 & 0.69819 & 0.09535 & 0.07084 & 0.16954 \\
\hline I feel it is best to avoid dealing with the batterer out of fear and concern for the victim's safety. & -0.02784 & 0.66415 & -0.22926 & -0.15211 & 0.05638 \\
\hline $\begin{array}{l}\text { I feel I can discuss issues of battering and abuse with a battering patient without further } \\
\text { endangering the victim. }\end{array}$ & 0.04849 & 0.37013 & 0.16097 & -0.16060 & 0.36676 \\
\hline I feel I can effectively discuss issues of battering and abuse with a battering patient. & 0.42092 & 0.45035 & 0.18031 & -0.33310 & 0.04278 \\
\hline I feel there are ways of asking about battering behaviour without placing myself at risk. & 0.02929 & 0.10581 & -0.05781 & -0.69755 & -0.14308 \\
\hline $\begin{array}{l}\text { I am reluctant to ask batterers about their abusive behaviour out of concern for my } \\
\text { personal safety. }\end{array}$ & 0.27271 & 0.34720 & 0.04736 & -0.37805 & 0.13946 \\
\hline There is not enough security at my work place to safely permit discussion of IPV with batterers. & 0.31894 & 0.41340 & 0.15924 & -0.33487 & -0.13521 \\
\hline I am afraid of offending patients if I ask about their abusive behavior. & -0.04354 & 0.08690 & 0.35737 & -0.34423 & 0.11797 \\
\hline When challenged, batterers frequently direct their anger toward health care providers. & 0.28291 & -0.42465 & 0.35432 & 0.09275 & 0.01984 \\
\hline \multicolumn{6}{|l|}{ Perceived self efficacy $($ Alpha $=0.653)$} \\
\hline I don't have the time to ask about IPV in my practice. & -0.05115 & 0.39604 & 0.41394 & -0.07883 & 0.12466 \\
\hline There are strategies I can use to encourage batterers to seek help. & 0.42964 & 0.27894 & 0.36603 & -0.02223 & 0.18061 \\
\hline There are strategies I can use to help victims of IPV change their situation. & 0.34168 & -0.04861 & 0.50922 & 0.01533 & -0.00193 \\
\hline I feel confident that I can make appropriate referrals for batterers. & 0.32581 & 0.57520 & 0.11702 & -0.32169 & 0.00439 \\
\hline I feel confident that I can make the appropriate referrals for abused patients. & -0.21933 & 0.39740 & 0.23915 & -0.00546 & -0.28631 \\
\hline I have ready access to information detailing management of IPV. & 0.20809 & 0.10889 & -0.11489 & 0.21976 & -0.02549 \\
\hline $\begin{array}{l}\text { There're ways I can ask batterers about their behaviour that will minimize risk to } \\
\text { the potential victim*. }\end{array}$ & -0.06281 & 0.05105 & -0.40880 & 0.59873 & 0.18511 \\
\hline \multicolumn{6}{|l|}{ System support items $($ Alpha $=0.635)$} \\
\hline $\begin{array}{l}\text { I have ready access to medical social workers or community advocates to assist in the } \\
\text { management of IPV. }\end{array}$ & -0.30131 & -0.08761 & -0.30675 & 0.07295 & -0.00318 \\
\hline I feel that medical social work personnel can help manage IPV patients. & 0.14441 & 0.33541 & 0.00333 & -0.11911 & 0.28585 \\
\hline I have ready access to mental health services should our patients need referrals. & -0.07753 & 0.04872 & 0.78585 & -0.08013 & 0.05002 \\
\hline I feel that the mental health services at my clinic or agency can meet the needs to IPV victims. & 0.07930 & 0.01621 & 0.67083 & -0.05988 & -0.08824 \\
\hline Eigenvalues. & 5.5888 & 2.7901 & 2.3794 & 2.0543 & 1.8469 \\
\hline$\%$ of variance explained. & $24 \%$ & $12 \%$ & $10 \%$ & $9 \%$ & $8 \%$ \\
\hline
\end{tabular}




\section{Scale Reliability}

The reliability coefficients (i.e. Cronbach's alphas) for the emerging subscales ranged between 0.60 - 0.67 (Table 2).

\section{Scale Correlations Testing for Scale Distinctiveness}

The significant bivariate correlation between the emerging sub-scales ranged between 0.25 and 0.31 (Table 1).

\section{Discussion}

This paper tested the factorial structure and internal reliability of the Domestic Violence Healthcare Provider Survey Scales (DVHPSS) before its application on a larger sample of Ugandan healthcare providers. The criteria for statistical scrutiny were defined apriori and are in line with recommendations for assessment of structural validity (Streiner \& Norman, 1989; Nunnaly, 1978; Carrol, 1957; Field, Aneja, \& Rosner, 2007; Cohen, 1988). In general, the study found the instrument applicable to the Ugandan context based on its factorial structure and scale reliability. A few exceptions incongruent with the original scale however were found, warranting acknowledgement. First, the item "I have ready access to information detailing the management of IPV" did not load significantly under any of the emerging factors, raising questions as to whether respondents identified with the issue. In other contexts, e.g. Sweden, USA, and Nigeria (Lawoko, Sanz, Helstrom, \& Castren, 2012; John \& Lawoko, 2010; Mauiro et al., 2000), this item loaded significantly under the Perceived self-efficacy scale. It is plausible that the issue of access to information detailing IPV management may have been variedly interpreted by participants in this context resulting in mixed/random responses and consequently accounting for the lack of significant correlation with any factor in general. Further scrutiny of this question will benefit from in-depth interviews with care personal in the studied context. Secondly, all other items of the Perceived self-efficacy scale loaded significantly under separate factors, indicating that they may not be representing a single-dimensional concept as portrayed in other contexts (Lawoko, Sanz, Helstrom, \& Castren, 2012; John \& Lawoko, 2010; Mauiro et al., 2000). These discrepancies may be a reflection of differences in healthcare provision and organisation between different societal contexts. For example, the questions of having strategies to help IPV victims loaded under the factor system support in our data, instead of perceived self-efficacy as portrayed in other contexts. The Ugandan sample may have viewed the issue of strategies in general as an issue more related to the care system rather than an issue of self-efficacy. The same could be argued regarding the issue of lack of time and having strategies to help victims change their situation.

Another unique observation for our data is the splitting of the victim/provider safety scale into two separate factors reflecting a victim and a provider safety scale respectively. Thus, the Ugandan sample appeared to distinguish self-safety from patient safety unlike elsewhere where these items clumped under a single safety factors. Again, plausible explanations for these discrepancies may lie in differences in the structure, organisation and provision of healthcare between indifferent societal contexts.

The factor structure of the Blame victim and Professional resistance/fear of offending clients' sub-scales appeared largely congruent with observations in some societies e.g. USA and Nigeria (John \& Lawoko, 2010; Mauiro et al., 2000), but at odds with others e.g. Sweden where a split into two separate factors was observed (Lawoko et al., 2012). In addition, the system support scale exhibited similar loadings as the original scale, congruent with observations in some contexts (John \& Lawoko, 2010; Mauiro et al., 2000) but at odds with others (Lawoko et al., 2012). These discrepancies thus drum for the necessity to assess factor structure of existing scales before their application in new contexts.

The DVHPSS scales exhibited good reliability, as tested with the internal consistency statistic (Cronbach's Alpha). In addition, correlations between the DVHPSS scales were consistent with theory (i.e. significant for scales where significance was expected and non-significant for scales where non-significance was expected). For instance, a significant correlation may from a theoretical perspective be expected between victim blame and professional role resistance, i.e. those likely to blame victims for abuse were also more likely to express conflicting professional roles in relation to IPV inquiries. Similarly, those likely to blame the victim were also more likely to express concerns that IPV inquiries may jeopardize victim/provider safety, indicating some form of resistance/negation towards IPV screening. These significant correlations were however not too high to suspect that the concepts measured a uni-dimensional construct. As such, the significant and non-significant bivariate correlations were an indication that the emerging factors represented distinct aspects of readiness to screen for IPV.

In summary, this data confirms the validity and reliability of the DVHSS for use in Uganda. Though scales largely exhibited similar factorial patterns as observed in other contexts, the Ugandan sample identified a more detailed breakdown of one of the initial underlying concepts (i.e. Victim/provider safety) into two distinct factors victim and provider safety respectively. In addition, a diffusion of the perceived efficacy items into separate scales was observed. This suggests that the two scales may not in the Ugandan healthcare context be measuring a unidimensional construct, and thus need to be scored separately to improve validity of the results. With regard to reliability on the other hand, the findings suggest that the scales in their original form are reliable and represent distinct aspects of readiness to screen for IPV as indicated by the cronbach's alphas and inter scale correlations respectively. In conclusion therefore, the DVHPSS thus can be applied in its current form in Uganda. It is however recommended that items be scored in accordance to the specific sub-scales revealed in this study to improve the structural validity of any assessment using this questionnaire in Uganda.

This study was designed to serve as a pilot for a larger future study to understand readiness to screen for IPV among healthcare personal in Uganda (using the DVHPSS). Notwithstanding, its weaknesses deserve some acknowledgement. Uganda being a unique context contrasted with USA where the instrument was developed, the item pool in the questionnaire may not be exhaustive of challenges to screening for IPV in the Ugandan context. Qualitative studies could reveal additional crucial challenges to screening specific to this context. The authors are currently involved in such studies.

Another word of caution concerns the differences in organisation of healthcare delivery within Uganda. The studied sample consist only workers at a regional referral hospital in northern Uganda. In the country, healthcare delivery differs hierarchically in organisation and capacity between national referral, regional referral, district hospitals or smaller healthcare units. The national and regional referral hospitals are better staffed 
and equipped to deliver health services than the district level hospitals and smaller health centres. Thus, the current results may be reflecting what is expected only at regional referral hospitals in Uganda, and may not be generalised to healthcare in Uganda as a whole.

\section{Acknowledgements}

We are most grateful to the Swedish institute of Social and Working life and the Marie-Curie program for funding this study. We are also grateful to Joseph Duku for data collection and imputation.

\section{REFERENCES}

Aimakhu, C. O., Olayemi, O., Iwe, C. A., Oluyemi, F. A., Ojoko, I. E., Shoretire, K. A., Adeniji, R. A., \& Aimakhu, V. E. (2004). Current causes and management of violence against women in Nigeria. Journal of Obstetrics \& Gynaecology, 24, 58-63.

doi:10.1080/01443610310001620314

Altman, D. G. (1991). Practical statistics for medical research. London, UK: Chapman \& Hall.

Altman, D. G. (1982). How large a sample? In S. M. Gore, \& D. G. Altman (Eds.), Statistics in practice. London: British Medical Association.

American Medical Association (1992). Diagnostic and treatment guidelines on domestic violence. Archives of Family Medine, 1, 39-47.

Brottsförebygande Rådet (BRÅ) (2009). Våld mot kvinnor och män i nära relationer: Våldets karaktär och offrets erfarenhet av kontakter och rättsväsendet. $B R \AA$ Rapport, 12.

Carroll, J. B. (1957). Biquartimin criterion for rotation to oblique simple structure in factor analysis. Science, 126, 1114-1115. doi:10.1126/science.126.3283.1114

Cohen, J. (1988). Statistical power analysis for behavioral sciences (2nd ed.). Hillsdale: Lawrence Erlbaum Associates.

Cronbach, L. J., \& Meehl, P. C. (1955). Construct validity in psychological tests. Psychological Bulletin, 52, 281-302. doi:10.1037/h0040957

Erikson, M. J., Hill, T. D., \& Siegal, R. M. (2001). Barriers to domestic violence screening in the padiatric setting. Pediatrics, 108, 98-102. doi: $10.1542 /$ peds. 108.1 .98

Fawole, O. I., Aderonmu, A. L., \& Fawole, A. O. (2005). Intimate partner abuse: Wife beating among civil servants in Ibadan, Nigeria. African Journal of Reproductive Health, 9, 54-64. doi: $10.2307 / 3583462$

Feldhaus, K. M., Kozio-Mclain, J., Amsbury, H. L., Norton, I. M., Lowenstein, S. R., \& Abbott, J. T. (1997). Accuracy of 3 brief screening questions for detecting partner violence in the emergency department. Journal of American Medical Association, 277, 13571361. doi:10.1001/jama.277.17.1357

Field, A. E., Aneja, P., \& Rosner, B. (2007). The validity of self-reported weight change among adolescents and young adults. Obesity, 15, 2357-2367. doi:10.1038/oby.2007.279

Garcia-Morena, C., Jansen, H., Ellsberg, M., Heise L., \& Watts, C. (2005). WHO multi-country study on women's health and domestic violence against women: Initial results prevalence, health outcomes and women's responses. Geneva: WHO.

Golding, J. (1999). Intimate partner violence as a risk factor for mental disorders: A meta-analysis. Journal of Family Violence, 14, 99-132. doi:10.1023/A:1022079418229

Harris, J. M., Kutob, R. M., Surprenant, Z. J., Maiuro, R. D., \& Delate, T. A. (2002). Can Internet-based education improve physician confidence in dealing with domestic violence? Family Medicine, 34, 287-292.

Heise, L., \& Garcia-Moreno, C. (2002). Violence by intimate partners. In E. Krug, L. L. Dahlberg, \& J. A. Mercy et al. (Eds.), World report on violence and health. Geneva: WHO.

John, I. A., Lawoko, S., Svanström, L., \& Mohammed, A. Z. (2010). Health care providers readiness to screen for intimate partner violence in Northern Nigeria. Violence and Victims, 25, 689-704. doi:10.1891/0886-6708.25.5.689

John, I. A., \& Lawoko, S. (2010). Assessment of the structural validity of the domestic violence healthcare providers' survey questionnaire: Using a Nigerian sample. Journal of Injury and Violence Research, 2, 75-83. doi:10.5249/jivr.v2i2.41

John, I. A., Lawoko, S., \& Oluwatosin, A. (2011). Acceptance of screening for intimate partner violence, actual screening and satisfaction with care amongst female clients visiting a health facility in Kano, Nigeria. African Journal of Primary Health Care \& Family Medicine, 3, 6.

Kishor, S., \& Johnson, K. (2004). Profiling violence: A multi-country study. Measures DHS, 53-63.

Koenig, M. A., Ahmed, S., Hossain, M. B., \& Khorshed, A. B. (2003). Women's status and domestic violence in rural Bangladesh: Individual and community-level effects. Demography, 40, 269-288. doi:10.1353/dem.2003.0014

Koss, M. (1990). The women's mental health research agenda: Violence against women. American Psychologist, 45, 374-380. doi:10.1037/0003-066X.45.3.374

Lawoko, S., Sanz, S., Helstrom, L., \& Castren, M. (2012). Assessing the structural and concurrent validity of a shortened version of the domestic violence healthcare providers' survey questionnaire for use in Sweden. Psychology, 3, 183-191.

Maiuro, R. D., Vitaliano, P. P., Sugg, N. K., Thompson, D. C., Rivara, F. P., \& Thompson, R. S. (2000). Development of a health care provider survey for domestic violence: psychometric properties. American Journal of Preventive Medicine, 19, 245-252. doi:10.1016/S0749-3797(00)00230-0

McFarlane, J., Parker, B., Soeken, K., \& Bullock, L. (1992). Assessing for abuse during pregnancy. Severity and frequency of injuries and associated entry into prenatal care. Journal of American Medical Association, 267, 3176-3178. doi:10.1001/jama.267.23.3176

Nunnaly, J. (1978). Psychometric theory. New York: McGraw-Hill.

Petersen, R., Gazmararian, J., \& Clark, K. (2001). Partner violence. Implications for health and community settings. Women's Health Issues, 11, 116-125. doi:10.1016/S1049-3867(00)00093-1

Rodríguez, M. A., Bauer, H. M., McLoughlin, E., \& Grumbach, K. (1999). Screening and intervention for intimate partner abuse: Practices and attitudes of primary care physicians. Journal of American Medical Association, 282, 468-474. doi:10.1001/jama.282.5.468

Roelens, K., Verstraelen, H., Van Egmond, K., \& Temmerman, M. (2006). A knowledge, attitudes and practice survey among obstetrician-gynaecologists on intimate partner violence in Flanders, Belgium. BMC Public Health, 6, 238. doi:10.1186/1471-2458-6-238

Short, L. M., Alpert, E., Harris, J. M., \& Surprenant, Z. J. (2006). A tool for measuring physician readiness to manage intimate partner violence. American Journal of Preventive Medicine, 30, 173-180. doi:10.1016/j.amepre.2005.10.009

Sohal, H., Eldridge, S., \& Feder, G. (2007). The sensitivity and specificity of four questions (HARK) to identify intimate partner violence: A diagnostic accuracy study in general practice. BMC Family Practice, 8, 49 .

Streiner, D. L., \& Norman, G. R. (1989). Health measurement scales a practical guide to their development and use. New York: Oxford University Press, Inc.

Thompson, R. S., Rivara, F. P., Thompson, D. C. et al. (2000). Identification and management of domestic violence-A randomized trial. American Journal of Preventive Medicine, 19, 253-263. doi:10.1016/S0749-3797(00)00231-2

Thorndike, R. M., Cunningham, G. K., Thorndike, R. K., \& Hagen, E. P. (1991). Measurement and evaluation in psychology and education (5th ed.). New York: Macmillan.

Tjaden, P., \& Thoennes, N. (2000). Extent, nature, and consequences of intimate partner violence: Findings from the national violence against women survey. Washington DC: Department of Justice (US).

Tolman, R., \& Rosen, D. (2001). Domestic violence in the lives of women receiving welfare. Violence against Women, 7, 141-158. doi: $10.1177 / 1077801201007002003$

World Health Organisation (2005). WHO multi-country study on women's health and domestic violence against women. Geneva: WHO. 